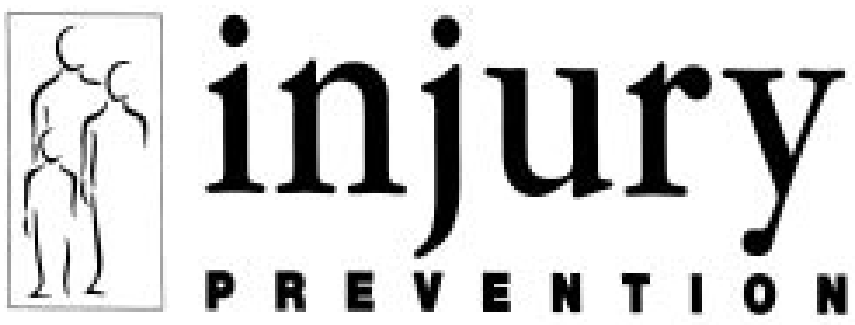

Journal of the International Society for Child and Adolescent Injury Prevention

\title{
Editorials
}

\section{Violence in the journal}

Several months ago members were asked whether ISCAIP and Injury Prevention should include intentional injuries. Some phrased the question, "Should we have violence in the journal?" My answer was a quick and emphatic "no" because I had visions of the editorial board engaged in sumo wrestling. But it later became clear that what was being asked was whether material dealing with violence had a home in the journal.

The issue arose again when it was decided that the ISCAIP meeting would be enlivened by a debate on this topic. The question was something along the lines of "Resolved: intentional injuries should be viewed differently from unintentional injuries". With some reluctance I agreed to speak in favour of the motion but made it clear that in doing so I would try to behave like the witty, provocative debaters whose oratorical skills I envy; skills that permit them to defend any position, including those with which they passionately disagree.

Accordingly, at the outset, I announced that I did not fully believe in the position I was assigned to defend, and, more importantly, that whatever I said was not the official view of the journal. I reminded the audience, as I now remind readers, that our policy has always been to welcome papers dealing with intentional injury (violence or suicide) just as warmly as we do those addressing the prevention of unintentional injury. There is no major disagreement among the editorial board with this policy. Unless we reverse ourselves the door of Injury Prevention will remain wide open to papers addressing suicide and violence prevention.

Although my team lost, the debate was fun, and some serious points were made. In the debate I noted that the main reason we have hitherto published so little on this topic is simply that we have had few contributions. I suggested that this may reflect the fact that the disciplines most heavily involved in violence prevention may be more comfortable publishing in social science journals rather than in one that is widely perceived as a "health" journal. But our intentions remain honorable and we hope more authors will consider Injury Prevention as a suitable venue for their findings

The present issue includes several excellent contributions on violence: three original articles, two guest editorials, and a special feature. Nevertheless, it is still reasonable to ask why there has not been more. Despite the arguments put forth in the opinion column (p 11), that the distinctions are largely pointless, I still believe there are some fundamental differences between unintentional and intentional injury, both with respect to research and preventive strategies.
The field of unintentional injury is older and consequently, better developed. Violence is more recent, more multidisciplinary, and is less obviously a health issue. In addition, there are few promising passive measures that can be applied to prevent violence. To be sure, banning handguns, strict gun control, or, perhaps, measures to make handguns safer, would be huge steps in the right direction. But for all such measures, as indeed, permeating this whole field, there are political considerations that rarely arise in the control of unintentional injuries. For violence, counterstrategies concentrate heavily on the agent or host. Rarely are there opportunities for prevention involving the environment. Finally, although a child injured from violence is just as wounded as one who falls from a swing on a playground, and should be equally a health concern, in many countries the violence agenda has been captured by disciplines outside health, as the dissent notes (p 13).

As you can tell, I remain torn between the views of the lumpers and the splitters but have no difficulty agreeing that the end result is an injury or fatality and that whatever form the injury takes, it is in the end, a health problem. In this respect, the Centers for Disease Control in the US is absolutely right to maintain that violence must remain part of its mandate. Nevertheless, the fact remains that the lion's share of programme initiatives addressing violence prevention is found elsewhere.

The same is true in academia. Until recently, the topic has been dominated by social scientists. However, based on an important event in which I participated last year, it may be that child health departments are on the verge on taking this important issue more seriously. The event I refer to is described in the guest editorial and in the section that follows. The latter is an editorial that Richard Krugman, Editor of Child Abuse and Neglect, and I wrote. Initially, we had intended to publish this in both our journals, but Krugman, being a Dean, and therefore much wiser than I, thought a more appropriate audience would be the readers of Pediatrics. (By the way, the title, Chicago's Hopes, is a weak pun on a popular American TV hospital drama.)

The Chicago meeting, whose origins are described by Tanz ( $\mathrm{p} \mathrm{8)}$ ), was unusual, to say the least, and may prove to be a landmark. What made it so special is that customarily universities and chairpersons compete with one another; rarely do they cooperate. It is exceptional for several chairpersons to agree to work together on a common task, which, in this case, is immensely challenging-how to control child violence. We wish these visionaries well and look forward to further updates. For starters, we include a follow up report by Kohrman and Christoffel p 3). 
One last word on this: the Chicago entente is ironic. This alliance is many steps ahead of where most pediatric departments anywhere in the world stand with respect to unintentional injury. Most still fail to recognize that this is

\section{Chicago’s Hopes *}

April is National Child Abuse Prevention Month in the United States, and last April there were several events that commemorated this annual reminder of the ongoing toll to children everywhere as a result of child abuse and neglect. We had the opportunity to participate in a unique celebration that took place in Chicago, which we thought should be brought to the attention of all child health professionals, especially those who find themselves chairs of academic departments of pediatrics.

Large urban areas have many children who are victims of both unintentional as well as intentional injury, and many urban areas, such as London, Chicago, New York, Philadelphia, Boston, Baltimore/Washington, Houston, and Los Angeles have several to many schools of medicine. Many of the departments of pediatrics in these schools have relatively few (if any) faculty who have child abuse and neglect or injury prevention as their clinical specialty or area of research interest. These faculty often struggle to have access to adequate populations or patients, as well as resources to fund their academic programs. Thus, the launching of a collaborative, city-wide violence prevention effort in Chicago last April is a sentinel event worth noting and, in our view, emulating as widely as possible.

\section{Testing the editor}

There are many hallmarks of a "good" editor-infinite tolerance, good spelling, and knowing when to use "that" $v$ "which" being among the most important. One characteristic that is rarely mentioned, however, is achieving a good balance between having strong personal views (in other words, being biased) while permitting-or even encouraging - contributions representing opposing views. I passed this test previously when we published the powerful dissent by Dorothy Robinson opposing bike helmet legislation. Readers will have little doubt where I stand on this debate, but Robinson's position was well argued and deserved to be aired.

In this issue, I am again put to the test. The lead paper by Girasek ( $p$ 19) shatters my long held cherished conviction that the use of the word "accident" is harmful to our goals. Readers may recall that this topic was debated in the first volume, and although I did not editorialize on it at the time, I repeatedly remind authors of our dislike of the "A"

\section{Falls in the elderly}

In the interests of full disclosure, it should be no secret that we continue to consider expanding the scope of the journal to include adults. A decision will be made in the near future, but in the meantime, one point should be made clear. We agree that many strategies to prevent injuries in children are likely to benefit older persons as well, especially the elderly and the disabled. Thus, reports based a problem worthy of their attention, let alone one in which important research can be done. Certainly, no others, to my knowledge, have joined forces in an attempt to solve either category of injury problem

Before this even, no one had ever seen the six chairs of the academic departments of pediatrics on the same stage before. But, as one said, "Why would you want to compete for market share in this area?" Why indeed! Nevertheless, the six chairs pledged to develop a city-wide program that would serve all the children in Chicago, would improve and standardize education in violence prevention at all the schools, and would, perhaps most importantly, permit the collaboration of all the faculty in all the departments in their clinical and research programs. Accordingly, the opportunities to obtain peer-reviewed grants, as well as public and private funding, for this point effort are substantially greater than was possible for the six schools trying to do this separately.

Research and clinical advances in the areas of violence, child abuse, and injury prevention have been slow to develop. Part of the reason is the lack of funding and the need to have access to large populations of children to do adequate research. The Chicago approach seems to us to be so sensible and so refreshing that we thought we needed to share this experience with others in child health.

${ }^{\star}$ Reprinted by permission of Pediatrics $(1998 ; 102: 1207)$

word. Like most injury prevention zealots, I was convinced "accident" usually conveyed the idea that the injury was not preventable.

I still think there is much truth to this, but the paper by Girasek was favorably reviewed and in spite of my opposite leaning bias, I, too, was impressed with the rigor of her work and had no hesitation agreeing it should be published. Her results point strongly to the conclusion that the general public, at least in the US, are more sophisticated in their interpretation of the word "accident" than many of us had assumed. Nevertheless, unless it serves a specific purpose, for example, to distinguish between the injury causing event and the injury itself, I still believe the word should be avoided. As indeed, should "accidents" themselves.

Bottom line? On this score at least, the editor again passes the test. Contributors holding seemingly outrageous ideas on this or other topics are encouraged to submit papers and are assured they will receive a fair review.

largely on data involving adults, but which have a clear preventive message applicable to children or adolescents, are welcome. The critical issue is for authors to establish the relevance to "our population" until such time as that population is defined differently.

I B PLESS Editor 